\title{
Preservación y restauración: entender el significado de la destrucción del patrimonio cultural
}

\author{
Pablo Avilés Flores | École des hautes études en sciences sociales \\ URL de la contribución <www.iaph.es/revistaph/index.php/revistaph/article/view/4107>
}

Uno de los objetivos de la conservación de objetos de interés cultural es la transmisión de conocimientos sobre la cultura y la historia de la humanidad a través de generaciones. Tras la pérdida de la biblioteca de Sarajevo, Arturo Pérez-Reverte afirmó que la destrucción de una biblioteca nunca es casual y está cargada de maldad y simbolismo (PÉREZ-REVERTE, 1998: 47). ¿Qué significa la devastación de estos objetos, cuyo valor cultural fundamenta su protección, así como su eventual restauración? Entender la razón por la que se arruinan monumentos, edificios y obras de arte permite limitar las pérdidas.

En su libro Playing Darts With Rembrandt, el historiador Joseph L. Sax observa que en la historia del arte no hay nada más lógico que la destrucción y el vandalismo (SAX, 2011: 16); por ello es erróneo reducir los episodios "iconoclastas" a actos irracionales. La historiadora Eleonora Bairati compara la destrucción y el vandalismo del patrimonio cultural a una "acción guiada ideológicamente y controlada atentamente". Los monumentos, las bibliotecas y en general todo artefacto cultural, poseen una dimensión textual que sirve de soporte a un mensaje. Puede decirse que estos textos-monumentos tienen una función pedagógica importante para la historia nacional y la memoria colectiva de una sociedad. En este sentido, Bairati también precisa que la finalidad de los actos destructivos es "exorcizar el poder simbólico" de los bienes culturales (BAIRATI, 2000: 171): el iconoclasta y el vándalo suprimen dichos bienes porque los consideran ideológicamente peligrosos; en algunos casos los bienes culturales vandalizados son incorporados al nuevo patrimonio una vez que su valor simbólico ha sido neutralizado o modificado.

La destrucción de bienes culturales puede ser considerada desde varios puntos de vista. En primer lugar, no es una práctica nueva en tiempos de guerra; sin embargo, debido a la inclusión de las ciudades en los escenarios bélicos, puede subrayarse la importancia del vínculo jurídico -evidenciado en los instrumentos legales nacionales o internacionales- entre la protección de la población civil y la de los bienes culturales. No puede dejar de señalarse que la destrucción del patrimonio cultural tiene frecuentemente motivaciones genocidas. Es en este sentido que Raphael Lemkin, el creador del concepto de genocidio y su primer teórico legal, incluyó la destrucción de obras de arte y de la cultura como actos genocidas (LEMKIN, 1933; ROBINSON, 1960).

En segundo lugar, desde un punto de vista histórico y filosófico, la preservación y restauración del patrimonio cultural no sólo busca sustituir con una copia un edificio, un monumento o un objeto único, sino que se trata de la preservación de lo que quizás sea el valor más profundo y duradero de los artefactos culturales: el símbolo transmitido. Esta concepción está ya presente en el testimonio de Marc Bloch publicado en 1946 bajo el título La extraña derrota. Bloch describe la lucha contra el fascismo como un enfrentamiento para evitar la desaparición de una parte de la historia: un combate decisivo sobre quién y cómo sería elaborado en el futuro próximo el relato histórico. Bloch entendió inmediatamente que la lucha contra el totalitarismo no concernía sólo al frente militar, sino a la memoria de la humanidad (BLOCH, 2003: 146):

"Sin embargo, ¿nos resignaremos a no ser más que un 'museo de antiguallas', como han declarado los italianos refiriéndose a sí mismos? No nos engañemos: ni siquiera tenemos la opción. Si alguien lo cree aún posible, que recuerde la suerte que nuestros enemigos reservan a los museos. Queremos vivir y, para ello, vencer." 
a debate Patrimonio, terrorismo y desastres naturales ¿Cómo prevenir y abordar los enormes daños al patrimonio cultural mundial?

| coordinan Francisco Javier López Morales, Francisco Vidargas

Aplicada a la idea del patrimonio, la reflexión de Bloch permite observar la repercusión directa de la preservación y del rescate de los artefactos culturales en la manera en la que se concibe y escribe la Historia. Al comparar el coleccionismo con la arqueología, Alain Schnapp señala que el dominio del pasado -la relación de la sociedad con el tiempo y la memoria histórica- se realiza en gran parte a través de la preservación y difusión de una serie de objetos (SCHNAPP, 1993: 13). El pasado es el resultado de un proceso y de una selección: puede decirse que el patrimonio cultural es un juicio de la sociedad sobre su pasado. La concepción contemporánea del patrimonio retoma el aspecto selectivo de la memoria y la dimensión aprehensible de la historia. Se trata de un eco, si cabe, de la leyenda del barco de Teseo conservado durante siglos por los atenienses gracias al reemplazo de las piezas inservibles por nuevas: a pesar de los constantes cambios de sus elementos, nadie se hubiera atrevido a decir que no se trataba de la misma nave en la que Teseo volvió de Creta.

Finalmente, la idea del patrimonio cultural reposa sobre el ideal de universalidad según el cual las artes y las ciencias pertenecen e interesan a todo el mundo civilizado. En palabras de Lemkin: "las contribuciones de cada sociedad a la cultura internacional ingresan al tesoro de la humanidad sin perder sus características propias" (LEMKIN, 1933: 5). Es por esa razón que la propiedad privada o pública de un bien cultural posee características particulares. Como lo explica Sax en el caso de la propiedad privada: la posesión no permite abusar de ese bien. El patrimonio justifica la regulación del poder público y provee una parte importante de las discusiones sobre la limitación de los derechos privados, la propiedad pública y el interés común concerniente no solamente a un país, sino a la humanidad entera (GILLMAN, 2010).

\section{BIBLIOGRAFÍA}

- BAIRATI, E. (2000) Alle origini del museo moderno: l'eredità della Rivoluzione nella crescita dei grandi musei europei dell'Ottocento. En Ideologie e Patrimonio storico-culturale nell'età rivoluzionaria e napoleonica. A proposito del trattato di Tolentino. Atti del convegno Tolentino, 18-21 settembre 1997. Roma: Ministero per i beni e le attività culturali, Ufficio centrale per i beni archivistici, 2000, pp. 165-89 (Pubblicazioni degli Archivi di Stato. Saggi 5)

- BLOCH, M. (2003) La extraña derrota. Testimonio escrito en 1940. Editado por Stanley Hoffmann. Traducido por Santiago Jordán Sempere. Barcelona: Crítica, 2003

- GILLMAN, D. (2010) The Idea of Cultural Heritage. Édition révisée. Leicester: Cambridge University Press, 2010

- LEMKIN, R. (1933) Les Actes constituant un danger général (interétatique) considérés comme délits de Droit des Gens. Rapport spécial présenté à la Vme Conférence pour I'Unification du Droit Pénal à Madrid (14-20 X 1933) (explications additionnelles). Paris: Éditions A. Pedone, 1933

- PÉREZ-REVERTE, A. (1998) Patente de corso (1993-1998). Editado por José Luis Martínez Nogales. Madrid: Alfaguara, 1998

- RoBINSON, N. (1960) The Genocide Convention. A Commentary. New York: Institute of Jewish Affairs, 1960

- SAX, J. L. (2011) Playing Darts with a Rembrandt. Public and Private Rights in Cultural Treasures. Ann Arbor: The University of Michigan Pres, 2011

- SChNAPP, A. (1993) La conquête du passé. Aux origines de l'archéologie. Paris: Carré, 1993 